\title{
MONOBLOC AORTO-MITRAL HOMOGRAFT AS A TREATMENT OF COMPLEX CASES OF ENDOCARDITIS
}

Jean-François Obadia, MD, PhD, ${ }^{\text {a }}$ Olivier Raisky, MD, ${ }^{\text {a }}$ Laurent Sebbag, MD, ${ }^{\text {a }}$ Sydney Chocron, MD, PhD, ${ }^{\text {b }}$

Christine Saroul, MD, ${ }^{\mathrm{c}}$ and Jean-François Chassignolle, MD, ${ }^{\mathrm{a}}$ Lyon, France

The treatment of complex valvular endocarditis remains a surgical challenge (ie, when facing a redo operation, ${ }^{1}$ double valvular disease, or large abscess caused by aggressive bacteria). In such a situation, we propose a technique that allows a large resection of all the septic tissue and a repair by means of a cryopreserved monobloc aorto-mitral homograft.

Clinical summary. A 16-year-old boy was operated on for resection of a subvalvular aortic stenosis. Two months later, postoperative endocarditis caused by Staphylococus aureus necessitated a reoperation. A mechanical bivalvular replacement was performed, and the follow-up was uneventful.

From the Cardiothoracic Unit, ${ }^{\mathrm{a}}$ the Cardiothoracic Unit, ${ }^{\mathrm{b}}$ and the Intensive Care Unit, ${ }^{\mathrm{c}}$ Hôpital Cardiologique, Lyon, France.

J Thorac Cardiovasc Surg 2001;121:584-6

Copyright (c) 2001 by The American Association for Thoracic Surgery

$0022-5223 / 2001 \$ 35.00+0 \quad \mathbf{1 2 / 5 4 / 1 1 1 3 7 5}$

doi:10.1067/mtc.2001.111375
This patient was 42 years old when he had a mandible fracture treated with an intermaxillary blockage. The patient presented with endocarditis caused by Kingella denitrificans. There was a large disinsertion of both prostheses, a paravalvular abscess, and a fistula between the aorta and the right atrium. A double valvular replacement redux associated with a closure of the communication was performed.

One month later, the abscess had increased, and the 2 prostheses were disinserted again (Fig 1). The hemodynamic results were unstable, and the patient was operated on for the fourth time. This reintervention (Fig 2) was done through a superior transseptal approach. ${ }^{2}$ The 2 prostheses and all the fibrous mitro-aortic tissue, including both trigones, were removed. This huge resection, enlarged to the roof of the left atrium and to the first $3 \mathrm{~cm}$ of the aortic root, allowed a complete resection of the paravalvular abscess. It left a large opening on the right and left atria, the left ventricle, and the aortic root. The 2 coronary ostia were preserved in the button, and their first $2 \mathrm{~cm}$ were mobilized. A cryopreserved monobloc aorto-mitral homograft was prepared with a Carpentier Physio

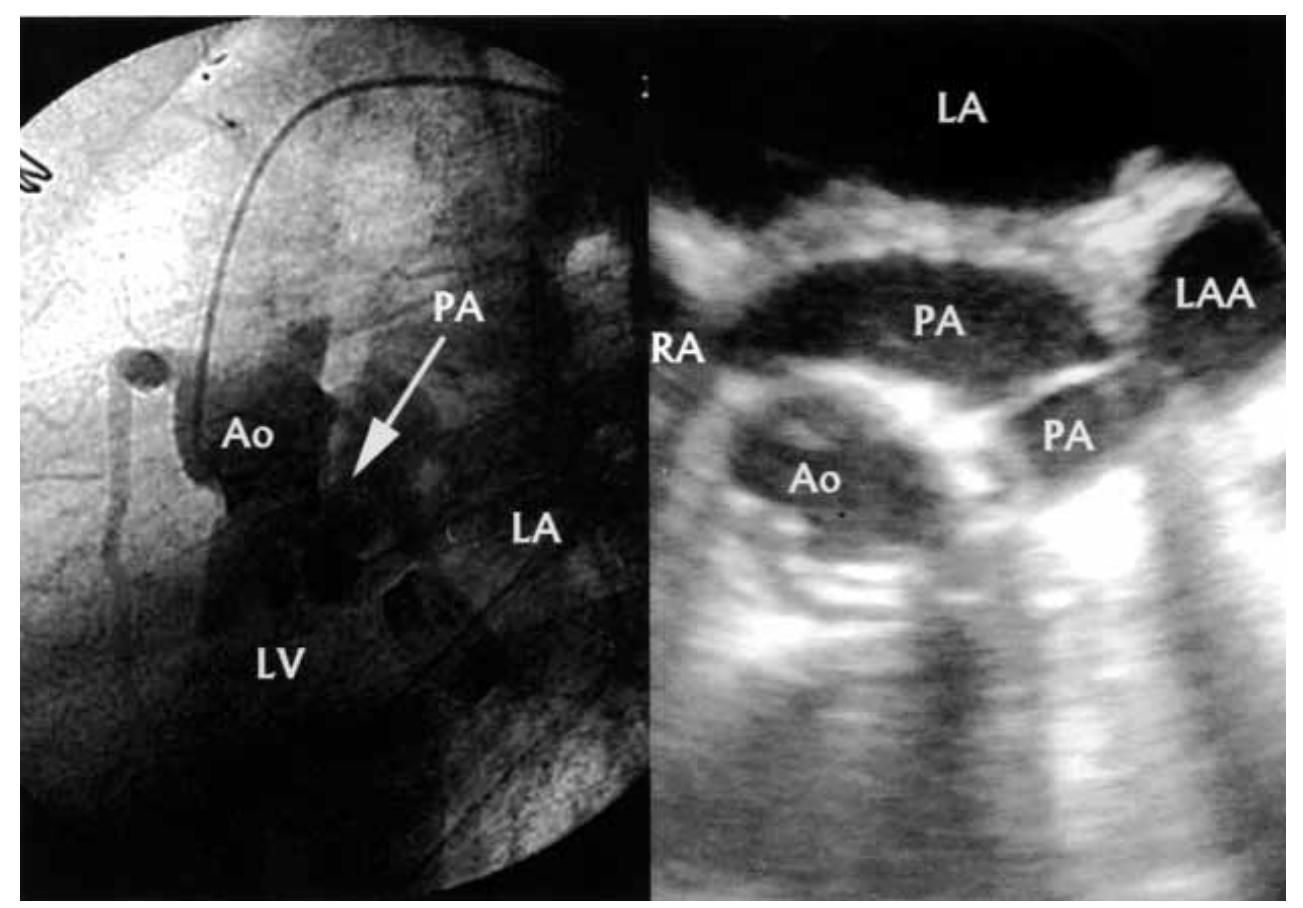

Fig 1. Preoperative angiography and echocardiography showing a large abscess associated with a paravalvular leak. Note the enlarged distance between the 2 prostheses caused by the extensive infective process. $P A$, Paravalvular abscess; $L A$, left atrium; $L A A$, left atrial appendage; $A o$, ascending aorta; $L V$, left ventricle; $R A$, right atrium. 


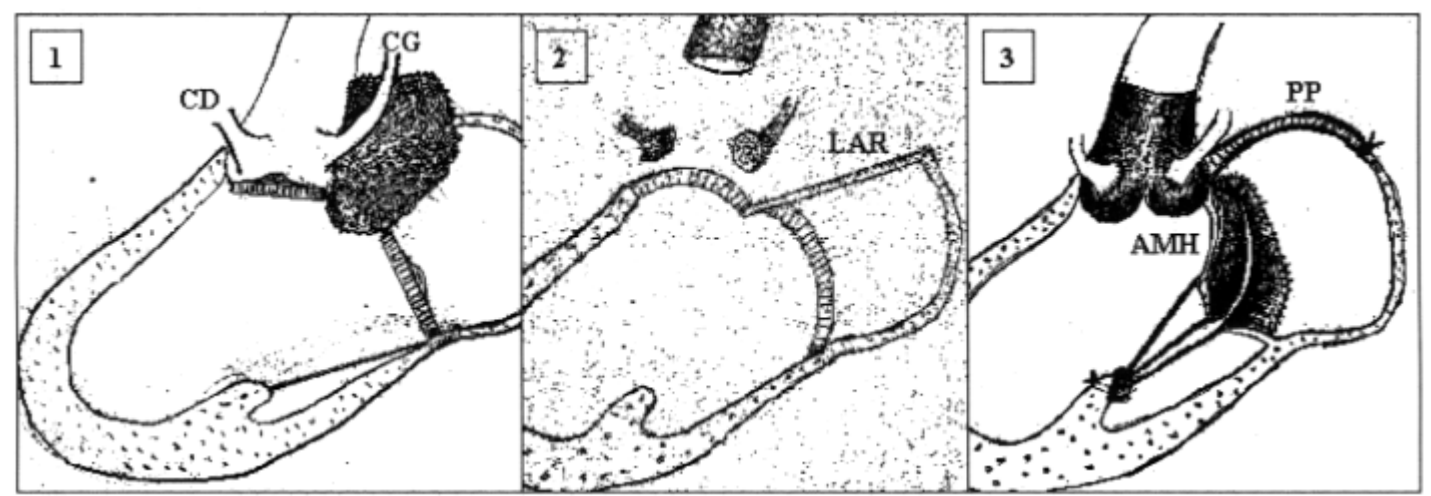

Fig 2. The 3 steps of the surgical procedure. 1, Exploration of the lesions. Note the paravalvular abscess around the left coronary artery. $C D$, Right coronary; $C G$, left coronary. 2, Resection of the 2 prostheses, the aortic root, the left atrial roof $(L A R)$, and all the paravalvular septic tissue. 3, Reconstruction with a monobloc aorto-mitral homograft $(A M H)$ and a pericardial patch $(P P)$.

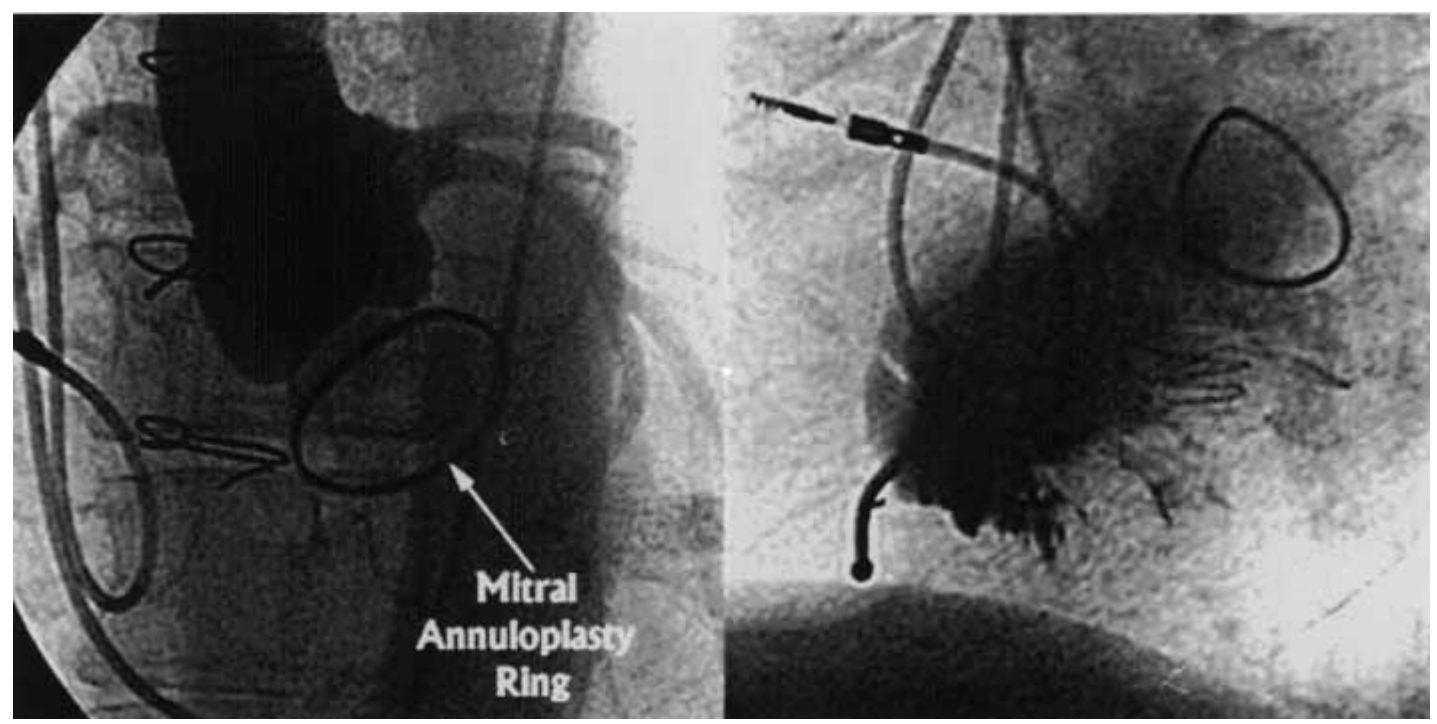

Fig 3. Angiogram on day 8 showing the anatomic repair and the aorto-mitral continuity without any leak on the 2 valves of the aorto-mitral homograft monobloc.

ring (Baxter Healthcare Corporation, Irvine, Calif) inserted extracorporeally. The papillary muscles of the left ventricle were dissected to receive the sutures of the papillary tips of the homograft. The posterior leaflet of the homograft was secured with a running suture. The aorto-mitral junction, including the 2 trigones of the monobloc homograft, was left intact. The remaining part of the aortic anulus was sutured with separated stitches. As a matter of fact, the mitro-aortic continuity and the mitral subvalvular apparatus were reconstituted. ${ }^{3}$ The left atrium roof was repaired with a pericardial patch. According to the Bentall technique, the 2 ostial buttons were reimplanted on the aortic root of the homograft, and the distal aorta was sutured terminally.
Cold blood cardioplegic solution was used for myocardial protection, and extracorporeal circulation was conducted under moderate hypothermia at $30^{\circ} \mathrm{C}$. Weaning off bypass was easy with no inotropic support after a crossclamp time of 212 minutes.

Results. The follow-up was favorable, with the patient extubated at 12 hours. A permanent pacemaker was implanted on day 6. Echocardiographic and angiographic follow-up performed on days 8 and 10 show perfect function of both homograft valves (Figs 3 and 4). There was no mitral leak or stenosis. There was no aortic leak, with a transvalvular gradient of $12 \mathrm{~mm} \mathrm{Hg}$. The echocardiographic data were stable after an 8-month follow-up period. 


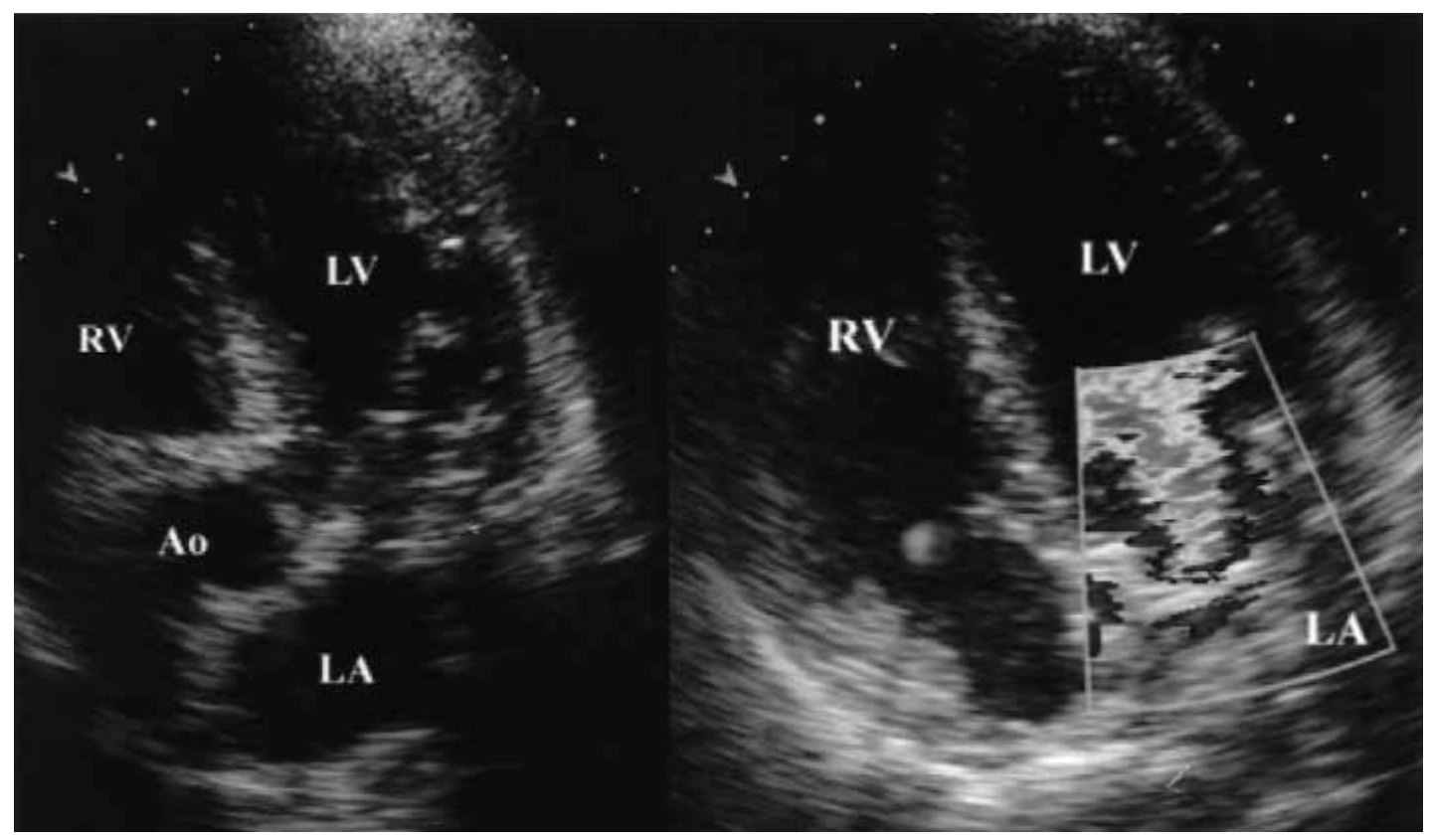

Fig 4. Echocardiogram on day 10. The aorto-mitral continuity is visible on the left (diastolic view). The mitral competence is attested on the right (systolic view). $L V$, Left ventricle; $L A$, left atrium; $R V$, right ventricle; $A o$, aorta.

Discussion. Usually aortic and mitral homografts are cryopreserved separately. ${ }^{4,5}$ The technique proposed herein is different and cannot be improvised because we need a disposable cryopreserved monobloc aorto-mitral homograft. Such a homograft was prepared for several months in our tissue bank. Actually, this concept seemed interesting to us, and the case herein reported represented a good indication for such a solution. This original approach comprises 2 steps. The first step is a large and complete resection of all the septic tissue, without any limitation. The valves themselves and also the anulus; the paravalvular and fibrous structures, including both trigones; the aortic root; and the left atrial roof can be largely resected. The second step is a bivalvular repair with a monobloc homograft.

Conclusion. This new approach is not a simple bivalvular replacement but a replacement extended to all the lesions as a result of the infective process (valves, anulus, trigones, left atrial roof, and aorta). This approach is particularly adapted to complex and destructive valve endocarditis.

Received for publication April 28, 2000; accepted for publication Sept 3, 2000.
Address for reprints: J. F. Obadia, MD, PhD, Hôpital Cardiologique, Avenue du Doyen Lépine, 69003 Lyon, France (E-mail: jean-francois.obadia@chu-lyon.fr).

\section{REFERENCES}

1. Bayer AS, Bolger AF, Taubert KA, Wilson W, Steckelberg J, Karchmer AW, et al. Diagnosis and management of infective endocarditis and its complications. Circulation 1998;98:2936-48.

2. Guiraudon GM, Ofiesh JG, Kaushik R. Extended vertical transatrial septal approach to the mitral valve. Ann Thorac Surg 1991;52:1058-62.

3. Obadia JF, Casali C, Chassignolle JF, Janier M. Mitral subvalvular apparatus: an experimental study with an isolated working pig heart model. Circulation 1997;96:3124-8.

4. Acar C, Tolan M, Berribi A, Gaer J, Gouezo R, Marchix T, et al. Homograft replacement of the mitral valve: graft selection, technique of implantation, and results in forty-three patients. J Thorac Cardiovasc Surg 1996;111:367-80.

5. Reardon MJ, Oury JH. Evolving experience with cryopreserved mitral valve allografts. Curr Opin Cardiol 1998;13:85-90. 